ANALYTICAL MODEL FOR NON-UNIFORM CORROSION-INDUCED CONCRETE CRACKING

Shangtong Yang ${ }^{1}$, Kefei $\mathrm{Li}^{2}$ and Chun-Qing $\mathrm{Li}^{3 *}$

${ }^{1}$ Department of Civil and Environmental Engineering, University of Strathclyde, Glasgow, G1 1XJ, United Kingdom.

${ }^{2}$ Department of Civil Engineering, Tsinghua University, Beijing, 100084, China.

${ }^{3}$ School of Civil, Environmental and Chemical Engineering, RMIT University, GPO Box 2476, Melbourne 3001, Australia.

\title{
ABSTRACT
}

Corrosion-induced concrete cracking is one of the major deterioration mechanisms for reinforced concrete structures. Evidently, the corrosion process is not uniform along the circumference of the reinforcement. To model the stress distribution in concrete and determine the initiation of concrete cracking, a realistic non-uniform corrosion model needs to be developed. In this paper, a time-dependent corrosion model, producing non-uniform expansion to concrete, is first established. The stresses in concrete are then formulated through the employment of complex functions. The time to initiation of concrete cracking is determined and related to a number of material, geometric and corrosion parameters. The derived analytical model is verified by comparing the results with those from experimental tests in literature. It can be concluded that this model is one of very few analytical models that can determine the stresses in concrete caused by non-uniform corrosion of reinforcement in concrete.

KEYWORDS: Durability-related properties; Fracture \& fracture mechanics; Cracks \& cracking.

* Corresponding author. Tel: +61 39925 2181. Email: chunqing.li@rmit.edu.au. 
Corrosion of reinforcement is a significant problem affecting the durability of reinforced concrete (RC) structures. Practical experience and experimental observations (Andrade et al., 1993, Li, 2003, Otsuki et al., 2000) suggest that corrosion affected RC structures deteriorate faster in terms of serviceability (e.g., cracking or deflection) than safety (e.g., strength). Consequently, corrosion can lead to premature deterioration of RC structures, causing concrete cracking, delaminating and de-bonding. For example, only $4 \%$ to $5 \%$ degree of corrosion (in terms of steel mass loss) can cause serviceability failure of RC structures as defined by corrosion-induced crack width (El Maaddawy et al., 2005). Moreover, the maintenance and repair costs for corrosion induced deterioration in RC bridges in the United States have been reported more than $\$ 5$ billion per year (Koch et al., 2002).

Realising the significance of the problem, considerable research has been conducted during the last few decades. Early work mainly focused on uniform corrosion along the circumference of the reinforcing rebar in concrete (Liu and Weyers, 1998). This was probably because most experiments on producing corrosion in reinforced concrete employed impressed current technique; such an accelerated corrosion method controls the corrosion rate, hence the degree of corrosion, by adjusting the current and/or the time of interval applied to the reinforcement. As such, the corrosion generated by the impressed current method is in a uniform manner along the rebar. Meanwhile, almost all of the analytical and numerical studies assume a uniform corrosion expansion exerting between the reinforcement and its surrounding concrete. Under the corrosion expansion, concrete has been often modelled as a thick-wall cylinder (Bazant, 1979, Pantazopoulou and Papoulia, 2001, Li et al., 2006). Liu and Weyers (1998) proposed an analytical solution for the time to surface cracking by presuming concrete linear elastic and the 
uniform corrosion development. This analytical model has soon been improved by a number of researchers, e.g., (Pantazopoulou and Papoulia, 2001, Li et al., 2006, Bhargava et al., 2006), who considered concrete as a quasi-brittle material, i.e., the fracture property of concrete being included in the models. These models can well address the corrosion-induced cracking behaviour, covering time to cracking initiation, time to surface cracking, surface crack width, etc. However, the limitation is that only uniform boundary condition can be applied to the formulation of the stress and strain in concrete.

More recently, modelling of corrosion-induced cracking of concrete has been focused on non-uniform corrosion progression at the interface between reinforcement and concrete. Due to the fact that chlorides, as well as moisture and oxygen, penetrates to the depth of the reinforcement at different rates on different sides of the concrete, it is very rare to have a uniform and general corrosion on the reinforcement. It has been reported (González et al., 1995) that the pitting caused localized deterioration is equivalent to about four to eight times that of the reinforcement under overall corrosion. To study the non-uniform corrosion caused structural deterioration, numerical approach, mainly finite element method (FEM), has played a dominating role (Jang and Oh, 2010, Pan and Lu, 2012, Zhao et al., 2011, Du et al., 2014). Jang and Oh (2010) considered a few of non-uniform distributions of corrosion products and simulated the stress states in concrete accordingly. Pan and Lu (2012) modelled the non-uniform corrosion caused crack propagation in concrete with FEM and the concrete as a heterogeneous material. Du et al. (2014) employed damage plasticity model to simulate the concrete cracking under non-uniform corrosion induced expansion. A number of parameters were investigated on their effects to the surface cracking. Zhao et al. (2011) proposed a Gaussian distribution for the non-uniform corrosion caused displacement and simulated the cracking behaviour of concrete by smeared crack model. Literature review suggests (1) the 
distribution of the non-uniform corrosion caused expansion has seldom been based on experimental test results but more on assumptions and; (2) no model has been developed in relating concrete cracking to some basic parameters for the non-uniform corrosion, e.g., corrosion rate. As pointed out in (Zhao et al., 2011), this is probably because there is an absence of reliable data which can characterize the actual non-uniform formation and expansion of the corrosion products.

Yuan and Ji (2009) conducted the accelerated corrosion tests on reinforced concrete samples in an artificial environmental chamber and obtained a non-uniform corrosion distribution along the interface between reinforcement and concrete. In their findings, only a half of the reinforcement, facing concrete cover, was corroded and the corrosion caused expansion was in a semi-elliptical shape. Amongst limited experimental data, the non-uniform distribution derived from Yuan and Ji (2009) can provide the reasonable inputs for modelling the non-uniform corrosion caused concrete cracking. Moreover, although numerical approaches are more powerful in terms of solving a wider range of problems, analytical solutions are more accurate and convenient for the practical application. It would be, therefore, ideal to have an analytical model on non-uniform corrosion induced cracking of concrete. In the analytical model, some key material and corrosion parameters, e.g., corrosion rate, can be related to the structural behaviour, e.g., time to cracking. However, the non-uniform stress distribution, along the hoop direction of the concrete cylinder, requires complex functions to be used in the analytical formulation. In this case, concrete can only be treated as an elastic material, with cracking initiation being modelled. The initiation of cracking in concrete marks the start of the structural deterioration of reinforced concrete structures. After that the structure usually degrades faster and reaches to limit states quickly. 
101 This paper attempts to develop an analytical model for non-uniform corrosion induced concrete

102 cracking. A time-dependent non-uniform corrosion model is first derived, based on realistic experimental results from literature. A cracking model is then formulated by using the complex

104 functions to account for the non-uniform stress distribution on concrete. A number of material, 105 geometric and corrosion parameters are considered in the analytical model. The initiation of the 106 concrete cracking is determined as a function of its service time.

\section{RESEARCH SIGNIFICANCE}

109 Although considerable research has been conducted on modelling corrosion-induced concrete

110 cracking problems, very few models have been proposed based on non-uniform corrosion of

111 reinforcement in concrete. Amongst these available models for non-uniform corrosion, most

112 employed numerical approaches while almost none on an analytical manner. However, it has

113 become a widely accepted fact that the corrosion of reinforced concrete is normally not

114 uniform. For accurate prediction of cracking caused by corrosion, it is necessary to consider

115 non-uniform corrosion expansion in the formulation of stress and strain in the concrete solid. It

116 is therefore imperative to derive a rational model for corrosion-induced concrete cracking to

117 achieve the cost effectiveness in the asset management of reinforced concrete structures. To the

118 best knowledge of the authors, this paper represents the first attempt in the analytical

119 formulation of time-dependent non-uniform corrosion induced concrete cracking.

\section{NON-UNIFORM CORROSION MODEL}

122 Concrete with an embedded bar subjected to an internal pressure at the interface between the

123 bar and concrete can be modelled as a thick-wall cylinder (Bazant, 1979, Pantazopoulou and

124 Papoulia, 2001, Tepfers, 1979). This is schematically shown in Figure 1(a), where $D$ is the 
125 diameter of the bar; $d_{0}$ is the thickness of the annular layer of concrete pores at the interface

126 between the bar and concrete; and $C$ is the concrete cover. Usually $d_{0}$ is constant once

127 concrete has hardened. The inner and outer radii of the cylinder are $a=D / 2+d_{0}$ and

$128 b=C+D / 2+d_{0}$.

129

The corrosion products (mainly ferrous and ferric hydroxides, $\mathrm{Fe}(\mathrm{OH})_{2}$ and $\left.\mathrm{Fe}(\mathrm{OH})_{3}\right)_{\text {) occupy a }}$ few times more space than the original steel. The corrosion products first fill in the annular pores in concrete around the reinforcing bar, with thickness $d_{0}$, but normally do not produce stresses in concrete. As corrosion propagates in concrete, a band of corrosion products forms, as shown in Figure 1(b). If the reinforcement corrosion is a uniform process along the circumference of the reinforcing bar, the band becomes a circular ring which causes uniform expansive pressure on the concrete cylinder ( $\mathrm{Li}$ et al., 2006). However, this is usually not realistic as discussed earlier. It has been found that (Yuan and Ji, 2009), the front of corrosion products for the half of rebar facing concrete cover is in a semi-elliptical shape, while corrosion of the opposite half of rebar is negligibly small and can be neglected.

The total amount of corrosion products $W_{\text {rust }}(t)$ can be assumed to distribute around the bar, occupying three parts as shown in Figure 1(c): the semi-elliptical band of corroded steel with maximum thickness $d_{c o-s t}$, the porous circular band $d_{0}$ and the semi-elliptical rust band with maximum thickness $d_{m}$. It should be noted that the semi-major axis for the semi-ellipse of corrosion front is $D / 2+d_{0}+d_{m} . W_{\text {rust }}(t)$ can thus be expressed as follows:

$$
W_{\text {rust }}(t)=W_{s}+W_{0}+W_{m}
$$


150 Where $W_{s}$ is the amount of rust replacing the corroded steel, $W_{0}$ is the amount of rust filling the

151 porous band $d_{0}$ and $W_{m}$ is the amount of rust in the band $d_{m} . W_{s}, W_{0}$ and $W_{m}$ can be derived 152 respectively as follows:

153

$$
W_{m}=\rho_{\text {rust }}\left[\frac{\pi}{2}\left(\frac{D}{2}+d_{0}\right)\left(\frac{D}{2}+d_{0}+d_{m}\right)-\frac{\pi}{2}\left(\frac{D}{2}+d_{0}\right)^{2}\right]=\frac{\pi \rho_{\text {rust }}}{2}\left(\frac{D}{2}+d_{0}\right) d_{m}
$$

$\alpha_{\text {rust }}$ is the molecular weight of steel divided by the molecular weight of corrosion products. It varies from 0.523 to 0.622 according to different types of corrosion products (Liu and Weyers, 1998). $\rho_{\text {rust }}$ is the density of corrosion products.

By substituting Equations (2-4) into Equations (1), it becomes:

$$
W_{0}=\frac{\pi \rho_{\text {rust }}\left(D+d_{0}\right) d_{0}}{2}
$$

168 By neglecting the second order of small quantities, i.e., $d_{0} d_{m}$ and $d_{0}^{2}, d_{m}$ can be derived as 169 follows:

170

$$
\frac{2 W_{\text {rust }}(t)}{\pi}\left(\frac{1}{\rho_{\text {rust }}}-\frac{\alpha_{\text {rust }}}{\rho_{\text {st }}}\right)=D d_{0}+d_{0}^{2}+\frac{D}{2} d_{m}+d_{0} d_{m}
$$

$d_{m}(t)$ in Equation (6) is the maximum corrosion-induced expansion along the interface to the

174 concrete cylinder under which the stress will be initiated in the cylinder. $d_{m}(t)$ determines the 
175 shape of the semi-ellipse which is the boundary condition of the concrete cylinder in deriving

176 stresses and strains in concrete.

177

178

179

180

181

182

183

184

185

186

187

188

189

190

191

192

193

194

In Equation (6), $W_{\text {rust }}(t)$ is related to the corrosion rate of the steel rebar and can be expressed as (Liu and Weyers, 1998):

where $i_{\text {corr }}$ is the corrosion current density in $\mu \mathrm{A} / \mathrm{cm}^{2}$, which is widely used as a measure of corrosion rate.

The units of the parameters in Equations (1-7) need to keep consistent. For the clarification and also the convenience of readers, the units are specified in Table 1.

To determine the displacement boundary condition of the concrete cylinder, the function of the semi-ellipse of the corrosion front needs to be derived. It is known that, in rectangular coordinate system, the function for an ellipse can be expressed as follows:

$$
\frac{y^{2}}{A_{L}^{2}}+\frac{x^{2}}{A_{S}^{2}}=1
$$

where $A_{L}$ is the half length of major axis and $A_{S}$ is the half length of the minor axis for an ellipse, as shown in Figure 2. The bottom half of the circular band $d_{0}$ is shaded for easier recognition of the three bands, e.g., $d_{c o-s t}, d_{0}$ and $d_{m}$. Based on the geometry in Figure 2, $A_{L}$ and $A_{S}$ can be obtained, i.e., $A_{L}=D / 2+d_{0}+d_{m}$ and $A_{S}=D / 2+d_{0}$.

Transforming to a polar coordinate system, Equation (8) can be rewritten as follows, 


$$
r=\frac{A_{L} A_{S}}{\sqrt{A_{S}^{2} \sin ^{2} \theta+A_{L}^{2} \cos ^{2} \theta}}
$$

200

201 202

203

204

205

206

207

208

209 where $0 \leq \theta \leq \pi$.

Substituting $A_{L}$ and $A_{S}$ in the above equation,

$$
r=\frac{\left(D+2 d_{0}+2 d_{m}\right)\left(D+2 d_{0}\right)}{\sqrt{\left(2 D+4 d_{0}\right)^{2}+16 d_{m}\left(D+2 d_{0}+d_{m}\right) \cos ^{2} \theta}}
$$

The displacement boundary condition of the concrete cylinder $\delta(\theta, t)$ can therefore be derived, with $d_{m}$ substituted in Equation (6):

$\delta(\theta, t)=\frac{\left[D+2 d_{0}+\frac{8 W_{\text {rust }}(t)}{\pi D}\left(\frac{1}{\rho_{\text {rust }}}-\frac{\alpha_{\text {rust }}}{\rho_{\text {st }}}\right)-4 d_{0}\right]\left(D+2 d_{0}\right)}{\sqrt{\left(2 D+4 d_{0}\right)^{2}+32\left[\frac{2 W_{\text {rust }}(t)}{\pi D}\left(\frac{1}{\rho_{\text {rust }}}-\frac{\alpha_{\text {rust }}}{\rho_{\text {st }}}\right)-d_{0}\right]\left[D+2 d_{0}+\frac{4 W_{\text {rust }}(t)}{\pi D}\left(\frac{1}{\rho_{\text {rust }}}-\frac{\alpha_{\text {rust }}}{\rho_{\text {st }}}\right)-2 d_{0}\right] \cos ^{2} \theta}}-\frac{D}{2}-d_{0}$

210

211

CONCRETE CRACKING MODEL

As discussed, the concrete is modelled as a thick wall cylinder. In polar coordinate system, the stress components in plane stress/strain elastic body can be expressed in terms of two arbitrary

214 complex functions $\gamma(z)$ and $\psi(z)(\operatorname{Sadd}, 2005)$ as follows:

215

$\sigma_{r}+\sigma_{\theta}=2\left\lfloor\gamma^{\prime}(z)+\overline{\gamma^{\prime}(z)}\right\rfloor$

216

$\sigma_{\theta}-\sigma_{r}+2 i \tau_{r \theta}=2\left[\bar{z} \gamma^{\prime \prime}(z)+\psi^{\prime}(z)\right] e^{2 i \theta}$

217 where $\sigma_{r}$ is the radial stress component, $\sigma_{\theta}$ is the hoop stress component and $\tau_{r \theta}$ is the shear 218 stress component.

220 Solving the Equations (12) and (13) the individual stress components can be derived as follows, 
$\sigma_{\theta}=\operatorname{Re}\left[2 \gamma^{\prime}(z)+\bar{z} \gamma^{\prime \prime}(z) e^{2 i \theta}+\psi^{\prime}(z) e^{2 i \theta}\right]$

$\tau_{r \theta}=\operatorname{Im}\left[\bar{z} \gamma^{\prime \prime}(z) e^{2 i \theta}+\psi^{\prime}(z) e^{2 i \theta}\right]$

225 The solution to the complex functions $\gamma(z)$ and $\psi(z)$ relies on solving the boundary conditions 226 of the hollow circular cylinder. There are two types of boundary conditions that can be 227 formulated, i.e., stress boundary condition and displacement boundary condition. These 228 conditions can be expressed as follows:

$\gamma(z)+z \overline{\gamma^{\prime}(z)}+\overline{\psi(z)}=i F(z) \quad$ for stress boundary condition

$\kappa \gamma(z)-z \overline{\gamma^{\prime}(z)}-\overline{\psi(z)}=2 G \delta(z) \quad$ for displacement boundary condition

231 where $F(z)$ is the resultant force exerting on a boundary, $G$ is the shear modulus, $\delta$ is the

232 displacement exerting on a boundary. $\kappa=3-4 v$ for plane strain problem and $\kappa=\frac{3-v}{1+v}$ for 233 plane stress problem, while $v$ is the Poisson's ratio.

234

235 As discussed, the expansive mechanism is modelled as displacement boundary condition to the 236 inner circle of the concrete cylinder. The inner boundary condition can be expressed as follows,

$$
\kappa \gamma\left(z_{1}\right)-z_{1} \overline{\gamma^{\prime}\left(z_{1}\right)}-\overline{\psi\left(z_{1}\right)}=2 G \delta\left(z_{1}, t\right), \quad z_{1}=a e^{i \theta}
$$

238 The outer boundary is the surface of the concrete cover. Therefore, the stress condition can be 239 formulated as follows,

$\gamma\left(z_{2}\right)+z_{2} \overline{\gamma^{\prime}\left(z_{2}\right)}+\overline{\psi\left(z_{2}\right)}=i F\left(z_{2}\right)=0, \quad z_{2}=b e^{i \theta}$ 
242 According to Laurent's Theorem, each complex potential can be expressed as a power series,

243 reducing the stress and/or displacement boundary problems to sets of simultaneous linear

244 equations in the coefficients of the two power series (MuSkhelishvili, 1953).

$245 \quad \gamma(z)=\sum_{-\infty}^{+\infty} \alpha_{n} z^{n}$

$246 \quad \psi(z)=\sum_{-\infty}^{+\infty} \beta_{n} z^{n}$

247 where $a \leq|z| \leq b$. Substituting Equations (21) and (22) into the stress boundary condition, i.e., 248 Equation (20), it becomes

$$
\sum_{-\infty}^{+\infty} \alpha_{n} z_{2}^{n}+z_{2} \sum_{-\infty}^{+\infty} n \overline{\alpha_{n}} \bar{z}_{2}^{n-1}+\sum_{-\infty}^{+\infty}{\overline{\beta_{n}}}_{z_{2}}^{n}=0, \quad \text { for } z_{2}=b e^{i \theta}
$$

250 For the sake of simplifying Equation (23), both sides of the equation are multiplied by $251 e^{-i m \theta}$ ( $m=0$ or integer), followed by integration with respect to $\theta$ from 0 to $2 \pi$. The boundary 252 condition (Equation 23) then becomes:

$253 \sum_{-\infty}^{+\infty} \alpha_{n} b^{n} \int_{0}^{2 \pi} e^{i n \theta} e^{-i m \theta} d \theta+b e^{i \theta} \sum_{-\infty}^{+\infty} n \overline{\alpha_{n}} b^{n-1} \int_{0}^{2 \pi} e^{-i(n-1) \theta} e^{-i m \theta} d \theta+\sum_{-\infty}^{+\infty} \overline{\beta_{n}} b^{n} \int_{0}^{2 \pi} e^{-i n \theta} e^{-i m \theta} d \theta=0$

254 It can be mathematically proved that, $\int_{0}^{2 \pi} e^{i n \theta} d \theta=0$ if $n$ is an integer or $2 \pi$ if $n=0$. Therefore 255 Equation (24) can be simplified as follows:

$256 \quad b^{2 m} \alpha_{m}+(2-m) b^{2} \bar{\alpha}_{2-m}+\bar{\beta}_{-m}=0$

257 Similarly, by substituting the power series, the inner displacement boundary condition, i.e., 258 Equation (19), becomes,

$$
\kappa \sum_{-\infty}^{+\infty} \alpha_{n} z_{1}{ }^{n}-z_{1} \sum_{-\infty}^{+\infty} n \bar{\alpha}_{n} \bar{z}_{1}^{n-1}-\sum_{-\infty}^{+\infty}{\overline{\beta_{n}}}_{z_{1}}{ }^{n}=2 G \delta(\theta, t), \quad \text { for } z_{1}=a e^{i \theta}
$$


260 Substituting $z_{1}=a e^{i \theta}$, multiplying $e^{-i m \theta}$ and integrating with respect to $\theta$ from 0 to $2 \pi$, 261 Equation (26) can be simplified as follows:

262

$$
\kappa a^{2 m} \alpha_{m}-(2-m) a^{2} \bar{\alpha}_{2-m}-\bar{\beta}_{-m}=\frac{a^{m} G}{\pi} \int_{0}^{2 \pi} \delta(\theta, t) e^{-i m \theta} d \theta
$$

263 By combining Equation (25) and (27), $\alpha_{m}$ and $\beta_{m}$ can be derived.

$264 \alpha_{m}=\frac{(2-m)\left(a^{2}-b^{2}\right) a^{2-m} G \int_{0}^{2 \pi} \bar{\delta}(\theta, t) e^{i(2-m) \theta} d \theta+\left[\kappa a^{2(2-m)}+b^{2(2-m)}\right] a^{m} G \int_{0}^{2 \pi} \delta(\theta, t) e^{-i m \theta} d \theta}{\pi\left\{\left(\kappa a^{2 m}+b^{2 m}\right)\left[\kappa a^{2(2-m)}+b^{2(2-m)}\right]-m(2-m)\left(a^{2}-b^{2}\right)^{2}\right\}}$

$\beta_{m}=\frac{\pi\left[\kappa a^{-2(m+1)}+b^{-2(m+1)}\right] \bar{\alpha}_{-m}+a^{-(m+2)} G \int_{0}^{2 \pi} \bar{\delta}(\theta, t) e^{-i m \theta} d \theta}{\pi\left(a^{-2}+b^{-2}\right)}$

267 To solve $\alpha_{m}$ and $\beta_{m}$ with regards to the integrals in Equations (28) and (29), $\delta(\theta, t)$, i.e., 268 Equation (11), needs to be expanded to Fourier series as follows (MuSkhelishvili, 1953):

$269 \delta(\theta, t)=\sum_{k=-\infty}^{+\infty} A_{k} e^{i k \theta}$

$270 \quad$ where $A_{k}=\frac{1}{2 \pi} \int_{0}^{2 \pi} \delta(\theta, t) e^{-i k \theta} d \theta$.

272 It is difficult to derive the explicit integrated form of series coefficients $A_{k}$; however, those

273 coefficients can be determined by numerical integration once all the other parameters are 274 evaluated.

276 Substituting Equations (30) into Equations (28) and (29), 
$277 \quad \alpha_{m}=\frac{(2-m)\left(a^{2}-b^{2}\right) a^{2-m} G \sum_{-\infty}^{+\infty} A_{k} \int_{0}^{2 \pi} e^{i(2-k-m) \theta} d \theta+\left[\kappa a^{2(2-m)}+b^{2(2-m)}\right] a^{m} G \sum_{-\infty}^{+\infty} A_{k} \int_{0}^{2 \pi} e^{-i(k+m) \theta} d \theta}{\pi\left\{\left(\kappa a^{2 m}+b^{2 m}\right)\left[\kappa a^{2(2-m)}+b^{2(2-m)}\right]-m(2-m)\left(a^{2}-b^{2}\right)^{2}\right\}}$

$279 \quad \beta_{m}=\frac{\pi\left[\kappa a^{-2(m+1)}+b^{-2(m+1)}\right] \bar{\alpha}_{-m}+a^{-(m+2)} G \sum_{-\infty}^{+\infty} A_{k} \int_{0}^{2 \pi} e^{-i(k+m) \theta} d \theta}{\pi\left(a^{-2}+b^{-2}\right)}$

280 Since $\int_{0}^{2 \pi} e^{i n \theta} d \theta=0$ if $n$ is an integer or $2 \pi$ if $n=0, \alpha_{m}$ and $\beta_{m}$ can be determined.

$281 \quad \alpha_{m}=\frac{2(2-m)\left(a^{2}-b^{2}\right) a^{2-m} G A_{2-m}+2\left[\kappa a^{2(2-m)}+b^{2(2-m)}\right] a^{m} G A_{-m}}{\left(\kappa a^{2 m}+b^{2 m}\right)\left[\kappa a^{2(2-m)}+b^{2(2-m)}\right]-m(2-m)\left(a^{2}-b^{2}\right)^{2}}$

282

$\beta_{m}=\frac{\left[\kappa a^{-2(m+1)}+b^{-2(m+1)}\right] \bar{\alpha}_{-m}+2 a^{-(m+2)} G A_{-m}}{a^{-2}+b^{-2}}$

283 where $m$ is an integer or 0 . The Fourier coefficients $A_{k}$ can be numerically determined in

284 MatLab and therefore $\alpha_{m}$ and $\beta_{m}$ are solved. By substituting $\alpha_{m}$ and $\beta_{m}$ into Equations (21) 285 and (22), the stress components, i.e., $\sigma_{r}, \sigma_{\theta}$ and $\tau_{r \theta}$, can be calculated from Equations (14) 286 (16).

\section{WORKED EXAMPLE}

289 To demonstrate the application of the derived model, a numerical example is undertaken on a

290 reinforced concrete beam originally investigated in $(\mathrm{Li}, 2003)$. The corrosion was achieved via

291 saltwater spray in a customer designed environmental chamber. The values of basic variables of 292 the structure and corrosion are shown in Table 2. 
294 With these values of the basic variables, first of all, the corrosion caused expansion 295 (displacement) can be obtained. $d_{m}(t)$ in Equation (6), defining the shape of the inner 296 displacement boundary condition of the concrete cylinder, is illustrated as a function of service 297 time (10 years), shown in Figure 3. Such a development of corrosion expansion is based on the 298 assumption that the corrosion rate $i_{c o r r}$ is time-dependent and equal to $0.3686 \ln (t)+1.1305$ $299 \mu \mathrm{A} / \mathrm{cm}^{2}$ (Li, 2003). The inset in Figure 3 represents an enlarged picture showing the initial 300 progression of the corrosion products. It can be seen that the maximum displacement $d_{m}(t)$ 301 starts to increase from zero at around 0.2 year, which is then followed by gradual increase in the 302 subsequent lifetime. Once $d_{m}(t)$ is obtained, the whole inner boundary condition of the 303 concrete cylinder, represented by Equation (11), can be determined.

Under the non-uniform expansion caused by reinforcement corrosion, the stresses can be 306 calculated from Equations (14) - (16). Figures 4 and 5 show the hoop and radial stresses, respectively, at the inner boundary of the concrete cylinder at 0.23 year. As illustrated in Figure $3081-\mathrm{c}$, the point of zero degree is located at the right middle of the inner boundary, with [0, $309-\pi / 2]$ represents the top right quarter and $[0, \pi / 2]$ represents the bottom right quarter, of the 310 concrete cylinder. The whole cylinder is symmetric against the y-axis, as shown in Figure 2. It 311 can be seen that the hoop stress changes along the inner boundary, most of which is under 312 tension. It has been found the highest hoop stress occurs at the location close to $15^{\circ}$. This is the 313 location where the crack is initiated. Although most of the concrete is in tension, a small part of 314 the concrete cylinder, from $80^{\circ}$ to $90^{\circ}$, is under mild compression in the hoop direction. It is 315 worth to mention that the maximum displacement $d_{m}(t)$ of the elliptical shape of the boundary 316 condition is added at the location of $90^{\circ}$. The combined tension and compression distribution of 317 hoop stress is quite different than previous findings by assuming uniform corrosion expansion 
where the hoop stresses of the concrete are all in tension, e.g., in ( $\mathrm{Li}$ and Yang, 2011). Under the

319 non-uniform expansion, the point at $90^{\circ}$ location appears to have the largest radial and compressive stress. At the region around $15^{\circ}$ the radial stress is in tension. It is very interesting to find, under the non-uniform corrosion expansion, the $90^{\circ}$ location is in compression in both hoop and radial directions, whilst the $15^{\circ}$ location is in tension in both directions. It should be noted that the positive hoop stress in Figure 4 represents tensile stress while the positive radial stress in Figure 5 represents compressive stress.

\section{VALIDATION OF THE DEVELOPED MODEL}

The derived model is verified by comparing the time to cracking initiation of the model and the experimental results from literature. According to the literature searched, almost all the test data regarding the time to cracking initiation are based on uniform corrosion development by 330 electric current method for accelerated corrosion. For the limited experimental research on non-uniform corrosion by utilizing artificial environmental chamber with salt spray function, no data on time to cracking initiation was provided. In light of comparing the derived model

333 with the test results, a special case of uniform corrosion was solved based on the developed

334 model. The stresses were then computed by the derived analytical equations and the time to 335 cracking initiation was determined, according to given tensile strength of the concrete. The 336 values for all inputs were made the same between the analytical model and the experiment. The 337 corrosion rate $i_{c o r r}$ is time-dependent in this model; but for the purpose of comparison, $338 i_{c o r r}=100 \mu A / \mathrm{cm}^{2}$ was used as was applied in the test (Mullard and Stewart, 2011). The 339 comparison to the experimental results is shown in Table 3. The results from the analytical 340 model and the experimental tests are in reasonable agreement. Further, it is interesting to find 341 that all the modelled times to cracking initiation are larger than the experimental ones. This is 
probably because the assumption of the ITZ in the model, i.e., it is totally stress-free when the

343 corrosion products are filling the band of ITZ. In fact, however, the filling of the corrosion

344 products in the porous ITZ can cause pressure. As a result, such an assumption of the ITZ will

345 underestimate the pressure induced by corrosion. The effect of the thickness $d_{0}$ of the ITZ will

346 be elaborated in the following section and illustrated in Figure 8.

\section{ANALYSIS AND DISCUSSION}

349 Corrosion rate, normally expressed as corrosion current density $i_{\text {corr }}$, has been considered one 350 of the key factors affecting the durability of reinforced concrete structures. A number of 351 researchers have been working on developing realistic models for the corrosion rate; in the

352 worked example, a time-dependent corrosion rate was employed. To investigate the effects of 353 the corrosion rate on the corrosion caused expansion, i.e., $d_{m}(t), 4$ constants corrosion rates are used, i.e., $i_{\text {corr }}=0.5 \mu \mathrm{A} / \mathrm{cm}^{2}, i_{\text {corr }}=1.0 \mu \mathrm{A} / \mathrm{cm}^{2}, i_{\text {corr }}=5 \mu \mathrm{A} / \mathrm{cm}^{2}$ and $i_{\text {corr }}=10 \mu \mathrm{A} / \mathrm{cm}^{2}$, as

355 presented in Figure 6(a). These corrosion rates are believed to have covered a wide range of 356 actual corrosion states of reinforced concrete structures. It can be seen that, as expected, the 357 increase of the corrosion rate will cause the increase of expansive displacement to the concrete. 358 The long-term effect is significant; for example, as the corrosion rate grows up to 10 times, the 359 10-year maximum displacement $d_{m}(t)$ could be increased to about 3.5 times. Such an increase 360 magnitude in the displacement boundary condition is crucial to the stress development in the 361 concrete cylinder. Nevertheless, the short-term effect is more sensitive, as shown in Figure $3626(\mathrm{~b})$. The corrosion rate $i_{\text {corr }}=10 \mu \mathrm{A} / \mathrm{cm}^{2}$ causes immediate form and progression of the rust 363 band at 0.01 year, whilst the pushing over of the rust band to the concrete cylinder is delayed to 3640.19 year for the corrosion rate $i_{\text {corr }}=0.5 \mu \mathrm{A} / \mathrm{cm}^{2}$. Further, the initial slope of the development 
of $d_{m}(t)$ is considerably steeper for higher corrosion rates. This means the initiation of cracking

366 might be very sensitive to the corrosion rate.

367

368 Figure 7 shows the development of $d_{m}(t)$ as the diameter of the reinforcing rebar changes.

369 When the diameter of the rebar increases from $12 \mathrm{~mm}$ to $20 \mathrm{~mm}$, the time to the initial 370 progression of $d_{m}(t)$ is delayed slightly, i.e., 0.06 year. The long-term development of $d_{m}(t)$

371 against the service time is also reduced as the diameter of rebar increases. This proves that, for 372 the same corrosion rate, larger size of rebar favours the corrosion caused expansion and hence delays the cracking initiation of the concrete.

Figure 8 demonstrates the effects of the ITZ thickness on the accumulation of the corrosion products. Three reasonable values of thickness are selected for the calculation of $d_{m}(t)$. As expected, the increase of the ITZ thickness can delay the occurrence of the expansive displacement. This is mainly because in this paper the porous ITZ is assumed to fully accommodate the corrosion products; as a result, the process of the accumulation of corrosion 380 products in ITZ, does not cause any stress or displacement. In Figure 8, it has been found that 381 the effect of ITZ thickness on the initial stage of $d_{m}(t)$ progression is quite considerable, with 382 the delay of roughly $83 \%$ from 0.18 year to 0.33 year for $d_{0}=12 e-6 m$ and $d_{0}=20 e-6 m$, 383 respectively. However, the long-term effects on $d_{m}(t)$ seems not very significant.

385 Figure 4 has shown the maximum tensile stress occurs at the location of around $15^{0}$, as a result 386 of the non-uniform corrosion expansion modelled. It is therefore worth to plot the hoop stress 
development history of this point. Figure 9 presents the hoop stress development as a function of service time for the point of $15^{\circ}$. The hoop stress for this point keeps constantly zero until 0.19 year which is followed by a very quick increase up to about $6 \mathrm{MPa}$ at 0.23 year. Most concrete will be cracked at such a level of tensile stress. The initial period of 0.19 year mainly represents the time for corrosion products propagating into the porous ITZ. Moreover, the initial 0.23 year represents for the initiation of cracking which marks the start of structural degradation.

Figure 10 shows the radial stress development for the point of $90^{\circ}$ under the derived non-uniform corrosion model. This point is where the maximum displacement $d_{m}(t)$ is applied and the maximum compressive stress occurs. Although the main failure type of this problem is fracture which is caused by tension, Figure 10 could be useful as to indicating the extent of compression at the time of cracking initiation.

By knowing the tensile strength of concrete $f_{t}$, the time to cracking initiation can be obtained. This is based on the failure criterion of the tensile stress reaches the tensile strength of concrete. As specified in Table 2, $f_{t}=5.725 \mathrm{MPa}$ is used in this study; hence the effect of corrosion rate on the time to initiation of cracking can be determined, as shown in Figure 11. Four corrosion rates are considered and fitted curve $\left(\mathrm{R}^{2}=1\right)$ was produced according to these four points. It can be seen that for minor corrosion extent, e.g., $i_{\text {corr }}$ is between $0.5 \mu \mathrm{A} / \mathrm{cm}^{2}$ and about $3.0 \mu \mathrm{A} / \mathrm{cm}^{2}$, the time to cracking initiation is very sensitive to the corrosion rate; however, when $i_{\text {corr }}$ is larger than $3.0 \mu \mathrm{A} / \mathrm{cm}^{2}$, the change in time to initiation of cracking is very small. 
411 In the paper, the stresses in concrete, subjected to non-uniform corrosion of the reinforcement,

412 have been formulated. The non-uniform stress distribution was analytically solved by using the 413 complex functions. The displacement boundary condition applied to the concrete cylinder was 414 derived as a function of the time-dependent corrosion rate. Further, the time to initiation of 415 concrete cracking has been determined based on the model developed, given values of the key 416 material and corrosion parameters. It has been demonstrated that the developed analytical 417 model can simulate the stresses in concrete caused by non-uniform corrosion and predict the 418 time to cracking initiation. The model has also been partially verified due to the limitation of 419 available test data on non-uniform corrosion directly. The developed model can be practically 420 used by industrial engineers and asset managers for their decision-making in regards to 421 corrosion induced concrete cracking problems.

\section{ACKNOWLEDGEMENT}

424 Financial support from European Commission via the Marie Curie IRSES project GREAT under FP7-PEOPLE-2013-IRSES-612665, Scottish Funding Council GRPe for early career

426 researcher exchanges and Australian Research Council under DP140101547, LP150100413 427 and DP170102211 is gratefully acknowledged. 
Andrade C, Alonso C and Molina FJ (1993) Cover cracking as a function of bar corrosion: part I-experimental test. Materials and Structures 26: 453-464.

Bazant ZP (1979) Physical model for steel corrosion in concrete sea structures - theory. Journal of the Structural Division-ASCE 105: 1137-1153.

Bhargava K, Ghosh AK, Mori Y and Ramanujam S (2006) Model for cover cracking due to rebar corrosion in RC structures. Engineering Structures 28: 1093-1109.

Du YX, Jin WL and Zhang R (2014) Modeling the cracking of cover concrete due to non-uniform corrosion of reinforcement. Corrosion Science, 89, 189-202.

EL Maaddawy, T, Soudki K and Topper T (2005) Analytical model to predict nonlinear flexural behavior of corroded reinforced concrete beams. ACI Structural Journal 102: 550-559.

González, JA, Andrade C, Alonso C and Feliu S (1995) Comparison of rates of general corrosion and maximum pitting penetration on concrete embedded steel reinforcement. Cement and Concrete Research 25: 257-264.

Jang, BS and Oh BH (2010) Effects of non-uniform corrosion on the cracking and service life of reinforced concrete structures. Cement and Concrete Research 40: 1441-1450.

Koch, GH, Brongers MPH, Thompson NG, Virmani YP and Payer JH (2002) Corrosion cost and preventive strategies in the United States. Federal Highway Administration, United States.

Li, CQ (2003) Life cycle modelling of corrosion affected concrete structures - propagation. ASCE Journal of Structural Engineering 129: 753-761.

Li, CQ, Melchers RE and Zheng JJ (2006) Analytical model for corrosion-induced crack width in reinforced concrete structures. ACI Structural Journal 103: 479-487.

Li CQ and Yang ST (2011) Prediction of concrete crack width under combined reinforcement corrosion and applied load. ASCE Journal of Engineering Mechanics 137: 722-731.

Liu Y and Weyers RE (1998) Modelling the time-to-corrosion cracking in chloride contaminated reinforced concrete structures. ACI Materials Journal 95: 675-681.

Mullard JA, and Stewart MG (2011) Corrosion-induced cover cracking: new test data and predictive models. ACI Structural Journal 108: 71-79.

Muskhelishvili NI (1953) Some basic problems of the mathematical theory of elasticity, Holland, P. Noordhoff Ltd.

Otsuki N, Miyazato S, Diola NB and Suzuki H (2000) Influences of bending crack and water-cement ratio on chloride-induced corrosion of main reinforcing bars and stirrups. ACI Materials Journal 97: 454-464.

Pan T and Lu Y (2012) Stochastic modeling of reinforced concrete cracking due to nonuniform corrosion: FEM-based cross-scale analysis. ASCE Journal of Materials in Civil Engineering 24(6): 698-706.

Pantazopoulou SJ and Papoulia KD (2001) Modeling cover cracking due to reinforcement corrosion in RC structures. ASCE Journal of Engineering Mechanics 127: 342-351.

Sadd MH (2005) Elasticity: theory, application and numerics, USA, Elsevier Butterworth-Heinemann.

Tepfers R (1979) Cracking of concrete cover along anchored deformed reinforcing bars. Magazine of Concrete Research 31: 3-12.

Yuan Y and Ji Y (2009) Modeling corroded section configuration of steel bar in concrete structure. Construction and Building Materials 23: 2461-2466.

Zhao Y, Karimi AR, Wong HS, Hu B, Buenfeld NR and Jin W (2011) Comparison of uniform and non-uniform corrosion induced damage in reinforced concrete based on a Gaussian description of the corrosion layer. Corrosion Science 53: 2803-2814. 
480 1. Units of the parameters

481 2. Values of basic variables used in cracking computation

482 3. Comparison of time to cracking initiation

483

484

485 
486

487

488

Table 1 Units of the parameters

\begin{tabular}{|c|c|}
\hline Parameter & Unit \\
\hline$D / d_{0}$ & $\mathrm{~mm}$ \\
\hline$\rho_{\text {rust }} / \rho_{\text {st }}$ & $\mathrm{kg} / \mathrm{m}^{3}$ \\
\hline$\alpha_{\text {rust }}$ & $\mathrm{n} . \mathrm{a}$. \\
\hline$W_{\text {rust }} / W_{s} / W_{0} / W_{m}$ & $\mathrm{mg} / \mathrm{mm}$ \\
\hline$d_{m}(t)$ & $\mathrm{m}$ \\
\hline$i_{\text {corr }}$ & $\mu \mathrm{A} / \mathrm{cm}^{2}$ \\
\hline$t$ & year \\
\hline
\end{tabular}

489

490 
Table 2 Values of basic variables used in cracking computation

493

\begin{tabular}{c|c|c}
\hline Symbol & Values & Sources \\
\hline$C$ & $31 \mathrm{~mm}$ & $\operatorname{Li}(2003)$ \\
$D$ & $12 \mathrm{~mm}$ & $\operatorname{Li}(2003)$ \\
$d_{0}$ & $12.5 \mu \mathrm{m}$ & Liu and Weyers (1998) \\
$E_{e f}$ & $18.82 \mathrm{GPa}$ & $\operatorname{Li}(2003)$ \\
$f_{t}$ & $5.725 \mathrm{MPa}$ & $\mathrm{Li}(2003)$ \\
$i_{\text {corr }}$ & $0.3686 \ln (t)+1.1305 \mu \mathrm{A} / \mathrm{cm}^{2}$ & $\mathrm{Li}(2003)$ \\
$\alpha_{\text {rust }}$ & 0.57 & Liu and Weyers (1998) \\
$v$ & 0.18 & Liu and Weyers (1998) \\
$G$ & $E /[2(1+v)]$ & Timoshenko and Goodier (1970) \\
$\rho_{\text {rust }}$ & $3600 \mathrm{~kg} / \mathrm{m}^{3}$ & Liu and Weyers (1998) \\
$\rho_{\text {st }}$ & $7850 \mathrm{~kg} / \mathrm{m}^{3}$ & Liu and Weyers (1998) \\
\hline \hline
\end{tabular}

494

495 
Table 3 Comparison of time to cracking initiation

497

\begin{tabular}{c|r|r|r|r|c|c}
\hline \hline Specimen & $\begin{array}{c}\mathbf{D} \\
(\mathbf{m m})\end{array}$ & $\begin{array}{c}\mathbf{C} \\
(\mathbf{m m})\end{array}$ & $\begin{array}{c}\boldsymbol{f}_{\boldsymbol{t}} \\
\mathbf{M P a})\end{array}$ & $\begin{array}{c}\boldsymbol{E}_{\boldsymbol{e f}} \\
\mathbf{( G P a )}\end{array}$ & $\begin{array}{c}\text { Time to cracking } \\
\text { initiation from } \\
\text { experiments (Mullard and } \\
\text { Stewart, 2011) (hours) }\end{array}$ & $\begin{array}{c}\text { Time to cracking } \\
\text { initiation from } \\
\text { the model (hours) }\end{array}$ \\
\hline 1 & 16 & 50 & 2.40 & 18.82 & 35 & 43 \\
2 & 27 & 50 & 2.40 & 18.82 & 26 & 59 \\
3 & 16 & 42 & 3.79 & 18.82 & 45 & 49 \\
4 & 27 & 36 & 3.79 & 18.82 & 43 & 68 \\
\hline
\end{tabular}

498 


\section{LIST OF FIGURES}

500 1. Illustration of non-uniform internal pressure caused by reinforcement corrosion

501 2. Schematic of the bands filled by corrosion products

502

3. $d_{m}(t)$ as a function of service time

503

4. Hoop stress distribution at the inner boundary of the concrete at the time of 0.23 year

504

5. Radial stress distribution at the inner boundary of the concrete at the time of 0.23 year

6. (a) Effects of the corrosion rate $i_{\text {corr }}$ on the development of displacement $d_{m}(t)$ as a function of service time; (b) enlarged view of $d_{m}(t)$ at the initial period

7. Effects of the diameter of the rebar D on the progression of $d_{m}(t)$

8. Effects of the thickness of the ITZ on the progression of $d_{m}(t)$

9. Hoop stress development as a result of the non-uniform corrosion process for the location of $15^{\circ}$

10. Radial stress development as a result of the non-uniform corrosion process for the location of $90^{\circ}$

513 11. Time to the initiation of concrete cracking as a function of the corrosion rate 


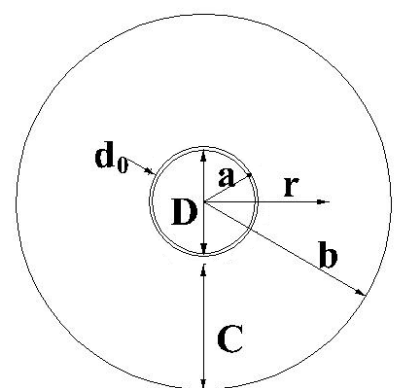

( a )

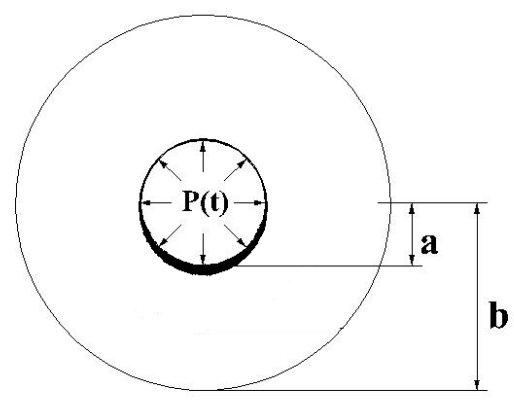

( b )

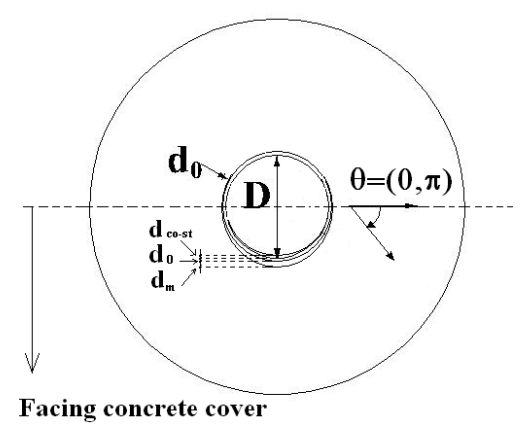

(c)

516

517 Figure 1 Illustration of non-uniform internal pressure caused by reinforcement corrosion 518 


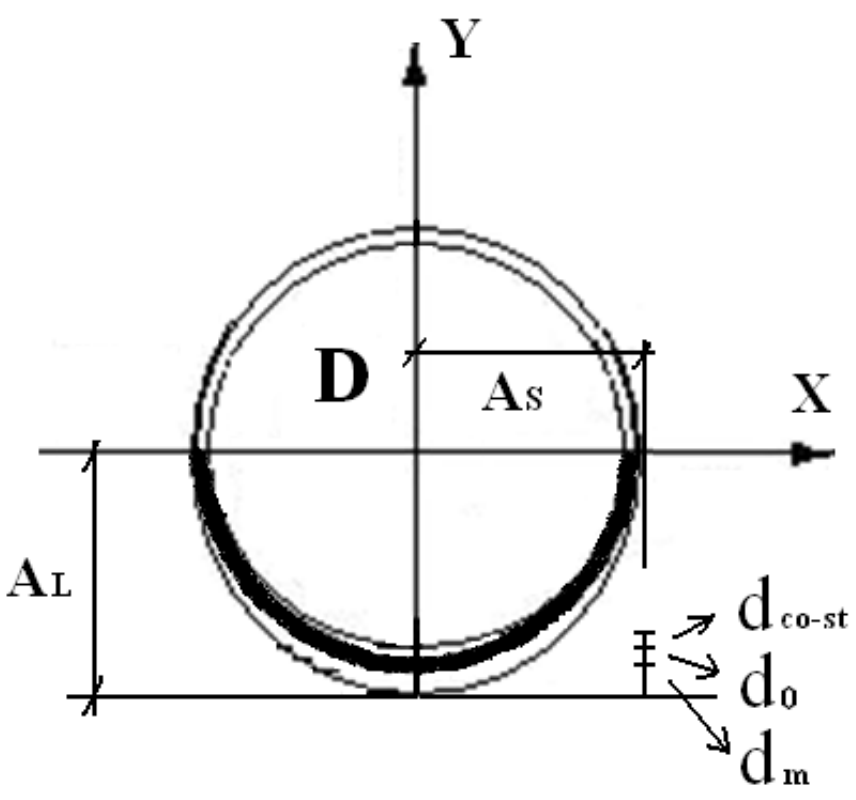

Figure 2 Schematic of the bands filled by corrosion products 523 


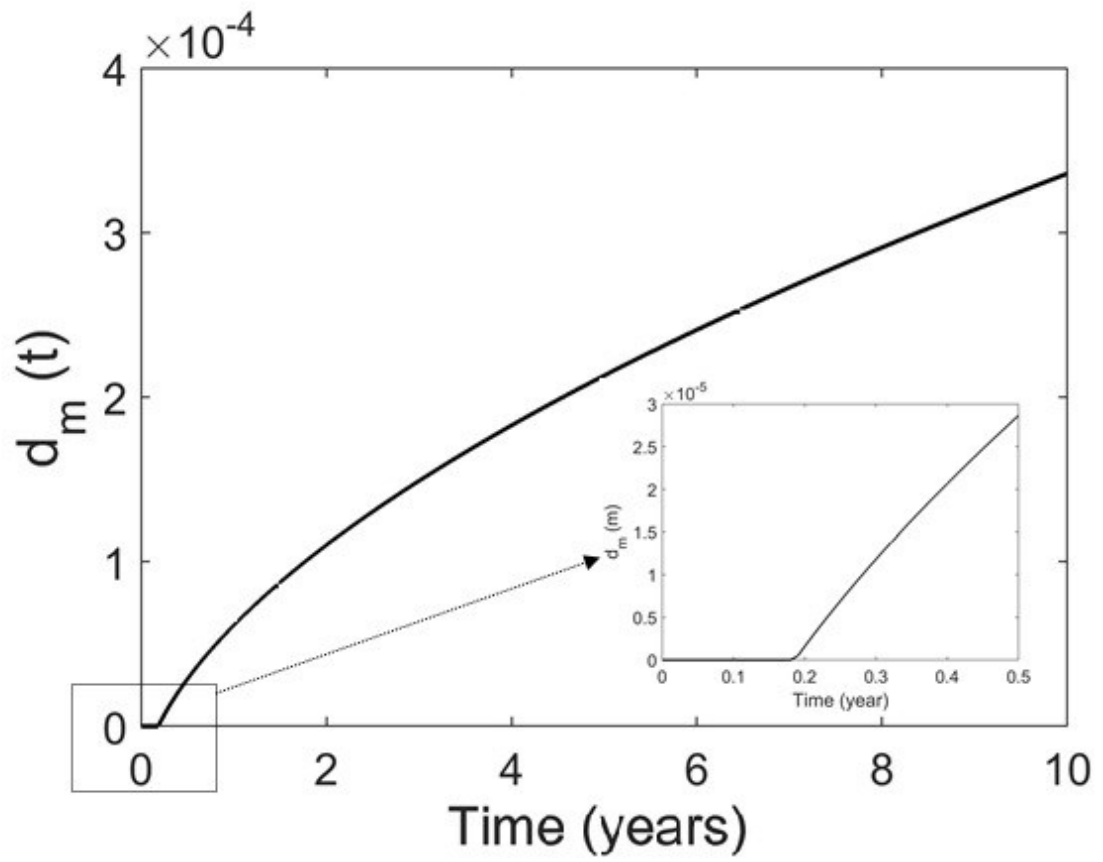

526

Figure $3 d_{m}(t)$ as a function of service time

527

528

529

530 


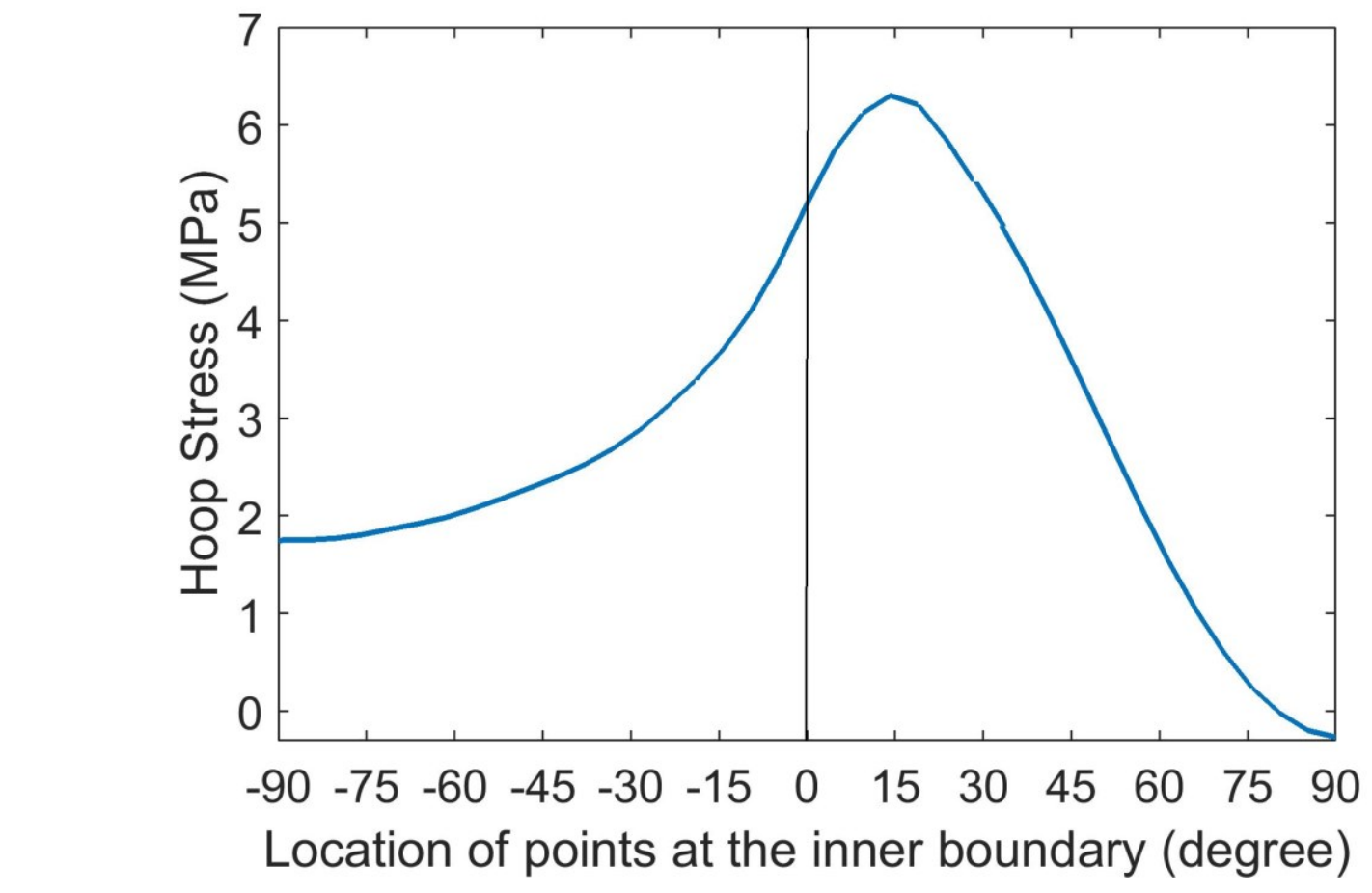

532 Figure 4 Hoop stress distribution at the inner boundary of the concrete at the time of 0.23 year 533 


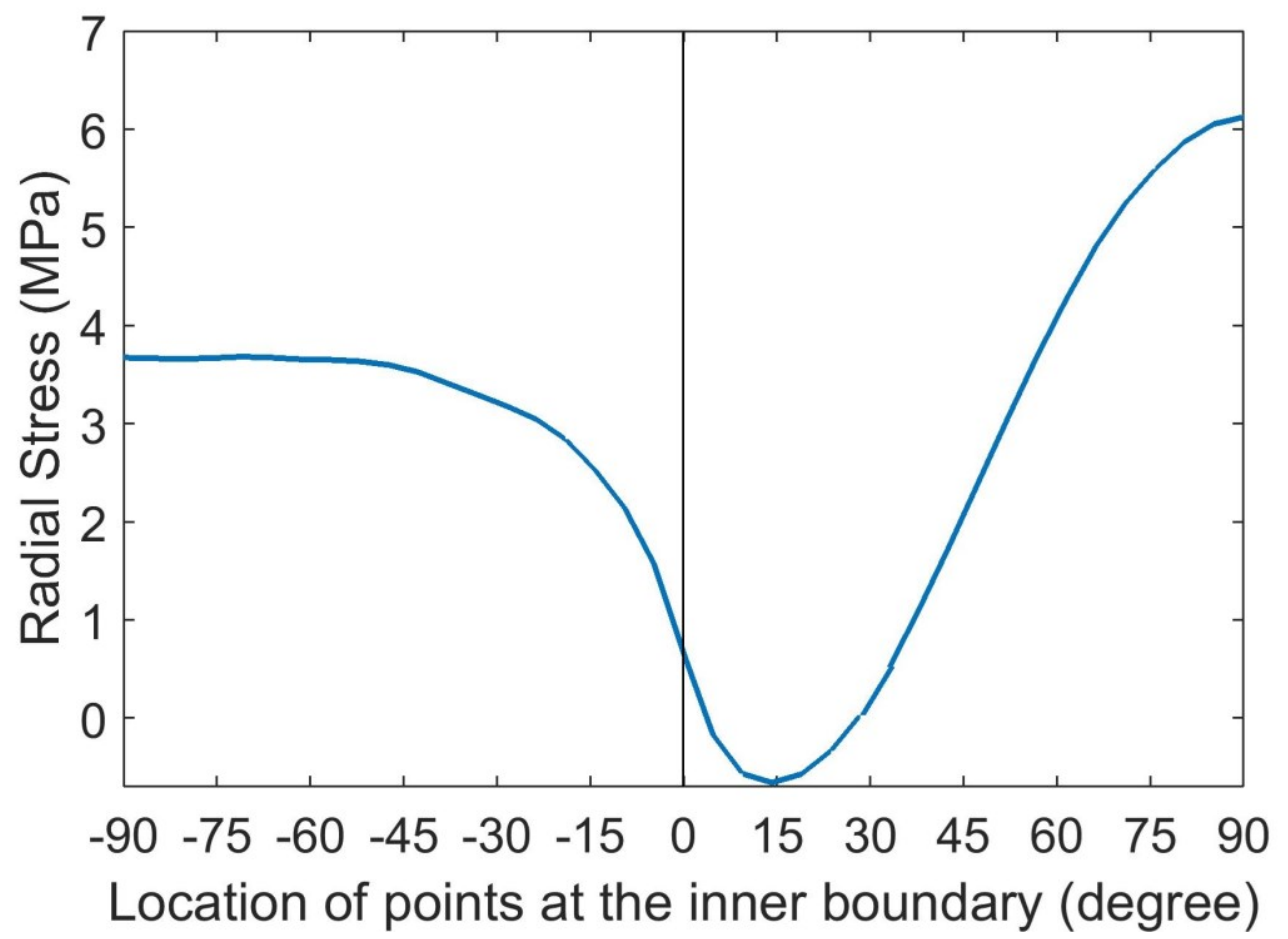

535 Figure 5 Radial stress distribution at the inner boundary of the concrete at the time of 0.23 year 536 

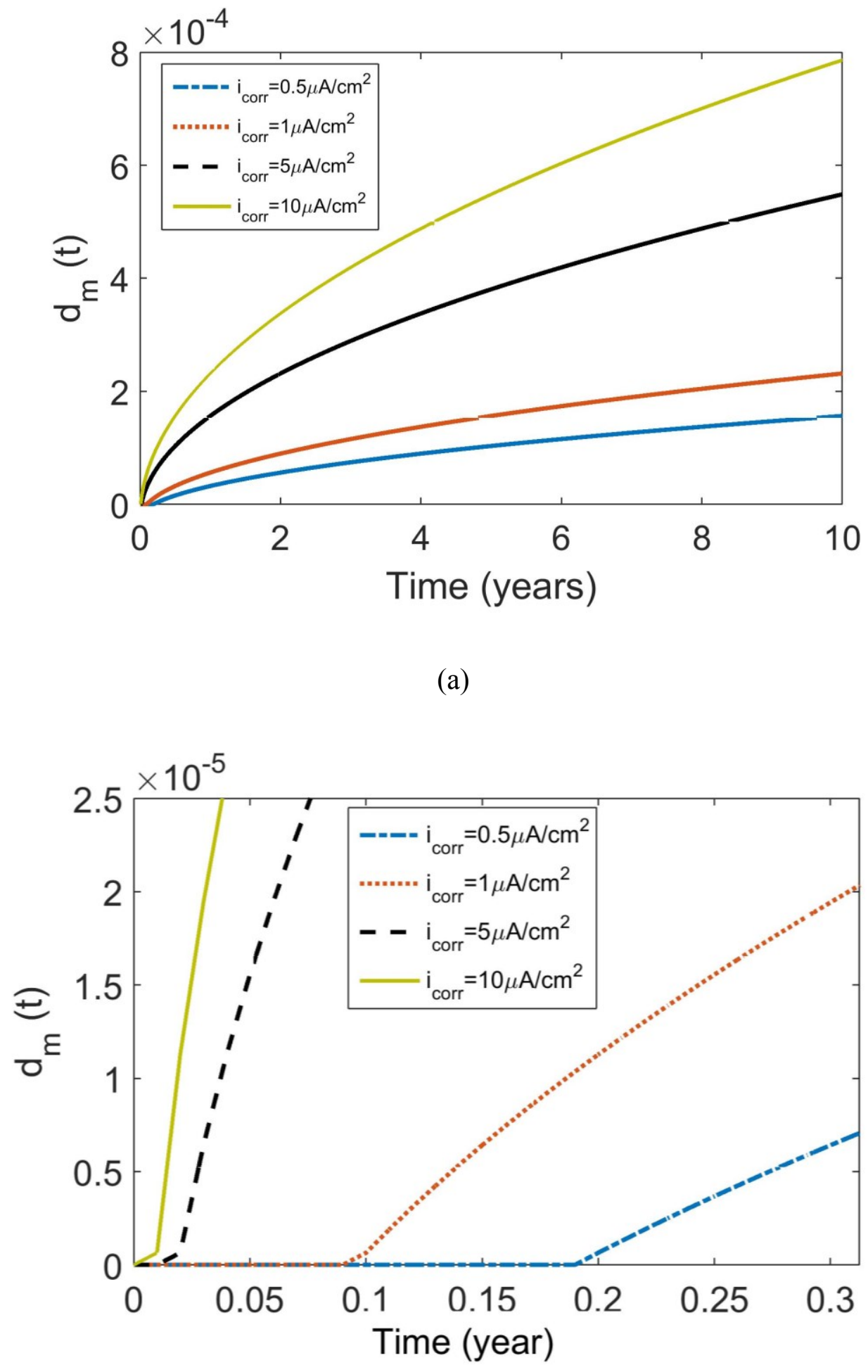

541 Figure 6 (a) Effects of the corrosion rate $i_{\text {corr }}$ on the development of displacement $d_{m}(t)$ as a function of service time; (b) enlarged view of $d_{m}(t)$ at the initial period 


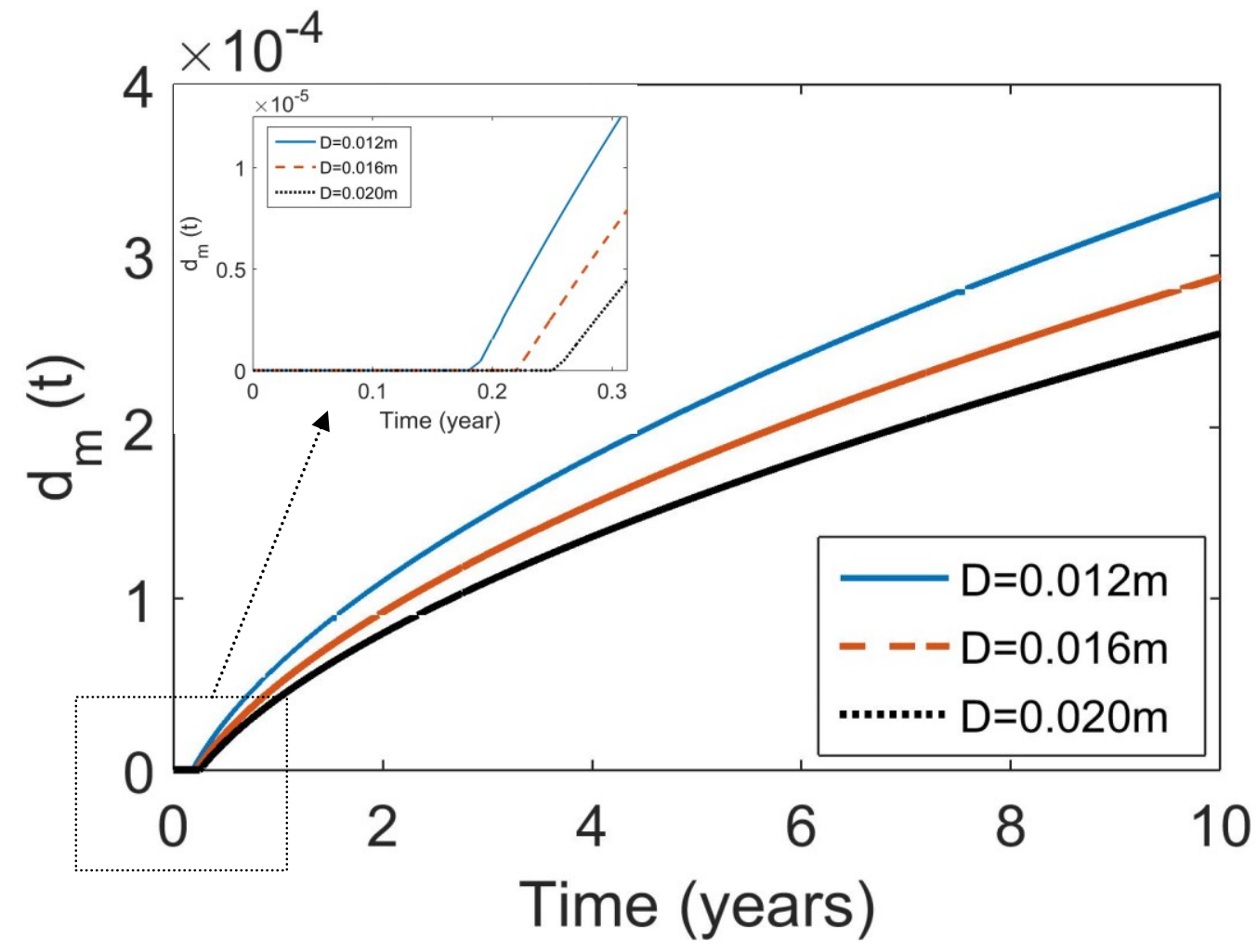

Figure 7 Effects of the diameter of the rebar D on the progression of $d_{m}(t)$ 


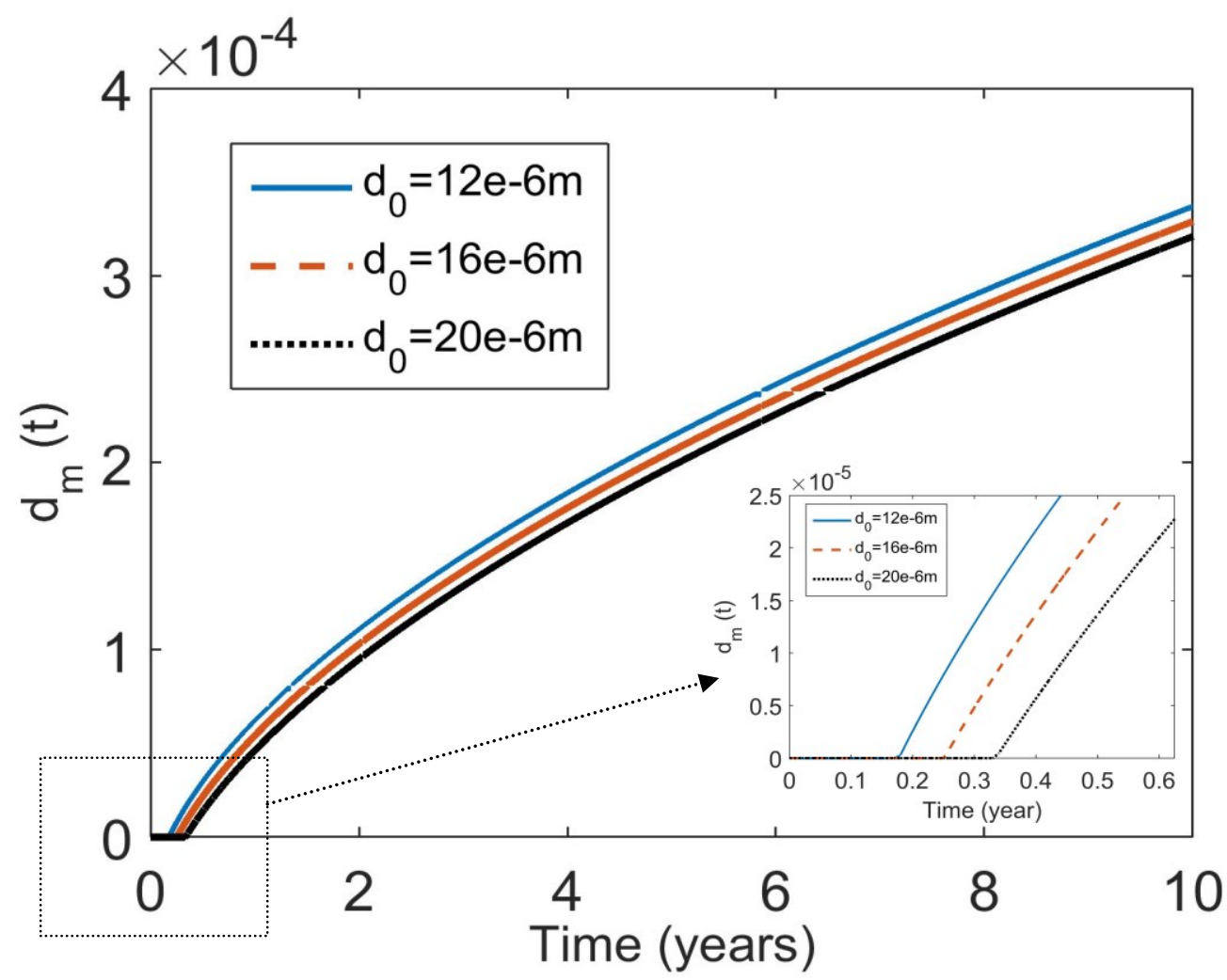

564

565

Figure 8 Effects of the thickness of the ITZ on the progression of $d_{m}(t)$

566 


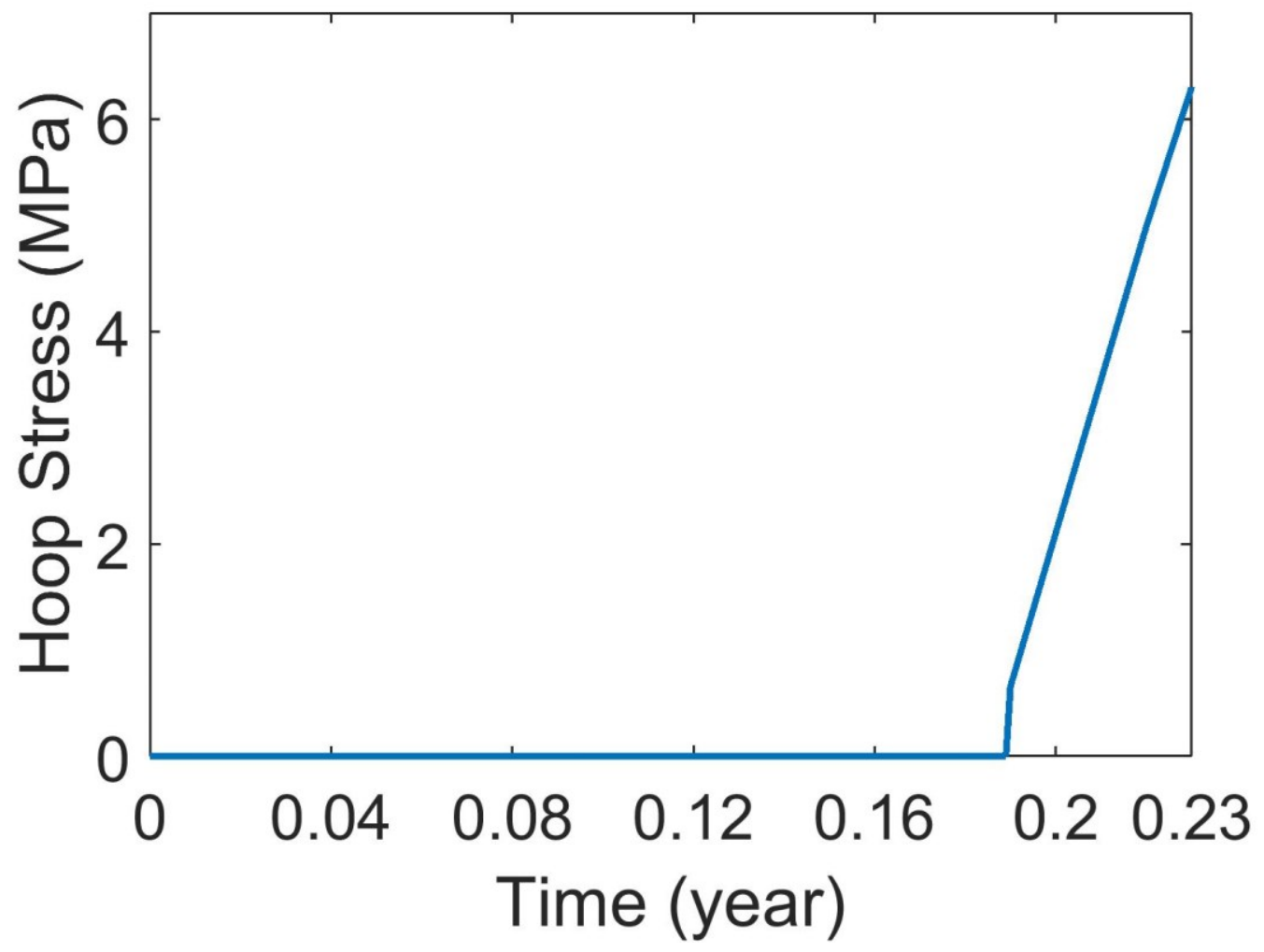

568 Figure 9 Hoop stress development as a result of the non-uniform corrosion process for the 569 location of $15^{0}$ 


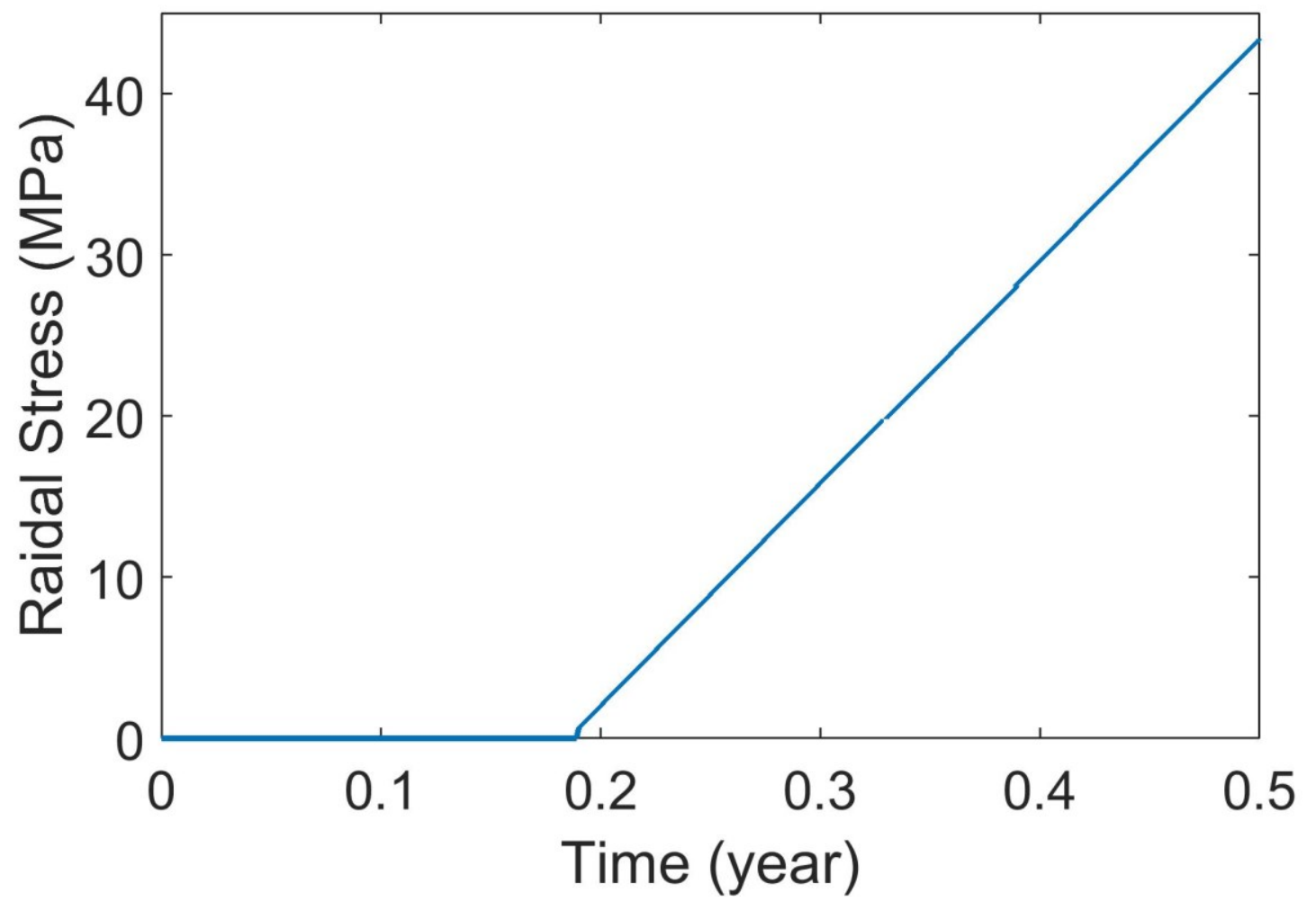

572 Figure 10 Radial stress development as a result of the non-uniform corrosion process for the 573 location of $90^{\circ}$

574 


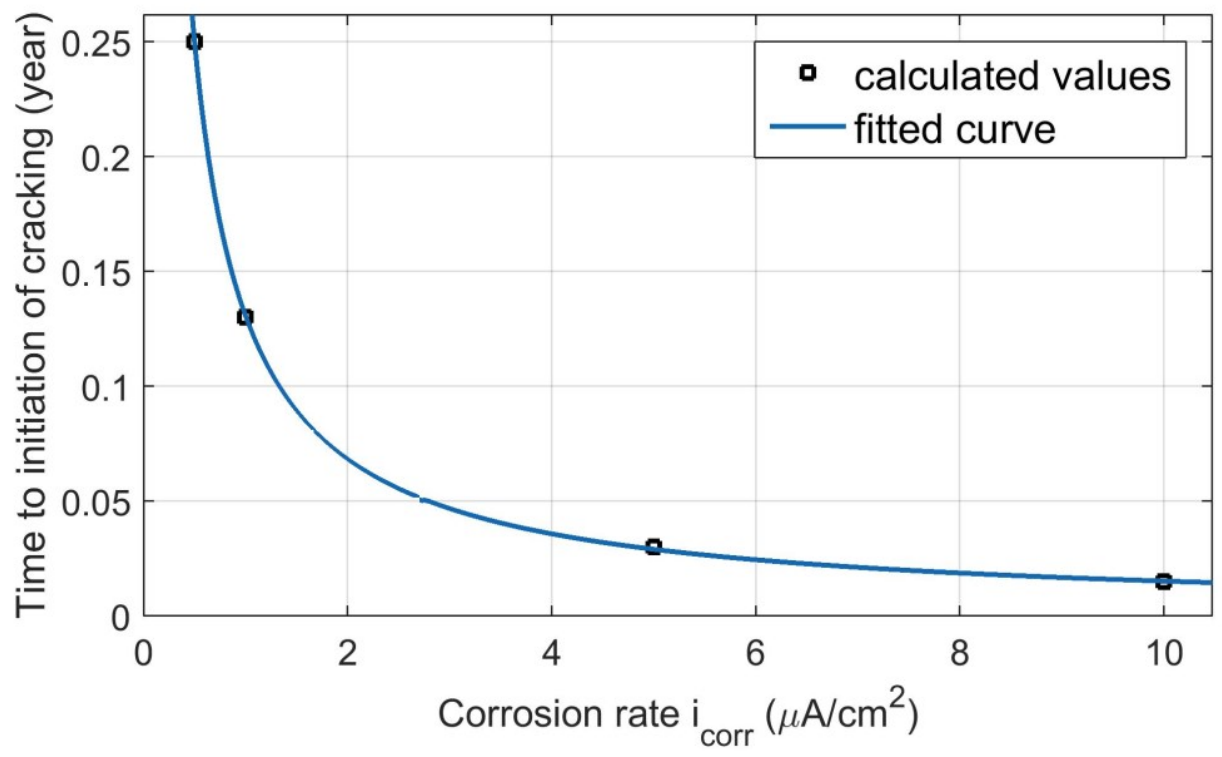

576 Figure 11 Time to the initiation of concrete cracking as a function of the corrosion rate 577

578 